\title{
TIYYATRO YöNETMENININ EĞITIMİ
}

\author{
Prof. Dr. Özdemir NUTKU \\ (Ankara Üniversitesi)
}

Aristoteles, insanda üç temel faaliyet olduğunu belirtir: Bunlar sirasıyla tanıma, eylem ve yaratıcıllk'tır. Ona göre bu üç faaliyet, birbiriyle ilişkili olarak üç ayrı çalışma alanı gerektirir: Tanıma teoretike, eylem praktike ve yaratıcılık poetike ile sağlanabilir. Isste Aristoteles in sözünü ettiği bu üç temel faaliyet, insanın kendini yansılayıp yeniden yarattığ 1 ve kendi varoluşunun nedenini anladığı tiyatro sanatınnın doğuşunda bulunur.

Bilimsel araștırma ve sanatsal yaratıcilık alanlarını kapsayan tiyatro eğitimi, böylece, üç temel akademik düzeyde ele alınmalıdır: 1) kuramsal dersler, 2) kuramları tamamlayıcı nitelikte çeşitli deneyleri içeren uygulamalar ve 3) yaratıcılığı geliştirecek seminerler. Yüksek öğretim kurumlarında bu düzeylerden biri savsaklanacak olursa; bașka deyişle bu düzeylerden biri eğitim programı dışında bırakılırsa tiyatro öğretimi ve eğitimi de eksik kalacaktır. Tek bașına kuramsal dersler tiyatroyu anlamaya yetmiyeceği gibi, yalnızca uygulama da yardımcı bilgi dağarcığını ve genel kültür anlayışını eksik bırakacaktır. Kuramsal derslerin uygulamasız bırakılması ya da tarihsel bilginin tiyatro tekniği öğretilmeaen verilmesi, tıpk1 operasyon üzerine bilgisi olup da amelıyat masasında hıç çalışmamış bır doktorun düşeceğı durumu ortaya çıkarır. Kuramsal bilgi mutlaka deneylerle desteklenmeli ve deneyler de seminerlerde yapılacak yaratıcı çalışma ile değerlendirilmelidir.

Üniversitede tiyatro öğretiminin geleneği -çok uzun olmasa dabizlere çok önemlı bir şey öğretmiştir: Edebiyat öğrenimi için kullanulan yöntemler tiyatro için hiç mi hiç geçerli olmamaktadır. Bunun bir neđeni, metin, edebiyat öğrencisi için temel malzeme iken, tiyatro öğrencisi için çok sayıdaki malzemelerinden bir tanesidir. Tiyatro öğrencisinin ölçüleri ve değerlendirme yöntemleri edebiyat öğrencisinin- 
kinden tamamen değişiktir. Tiyatro olgusunun varedilmesinde çeşitli öğelerin birbiriyle kaynaștırılması, bu öğelerin uyumlu bir biçimde sonuçlandırılması gerektiğinden, bu alanın değerlendirmesi, hem kuramsal, hem deneysel olmak üzere, birçok açıdan gerçekleştirilir. Tiyatro sanatının kollektif niteliği, edebiyattan daha değişik yöntemler gerektirdiği kadar, öğrencileri yetiștirmede yeni eğitim yollarını zorunlu kılmaktadır.

Bugün hâlâ -az da olsa- tiyatronun üniversitede yeri olmadığını ya da üniversitelerin teknik uygulamalarla değil, yalnızca "entelleklektüel" konularla uğraşması gerektiğini düşünenler vardır. Başka bir tipik eğilim de, teknik uygulamanın, akademik disiplinlerin saygınlğının altında olduğu yanılgısıdır. Kanımca, bu tür bir kendini beğenmişlik, uygulama çalışmalarının "entellektüel" çalışmaların altında bulunduğunu sanan düşünce sisteminden doğmaktadır. Ama şurası kesin ki, bir doktor operatörün pratik bilgisi ve el yeteneği, bir türlü oyun yazarı olamamış bir kişinin "entellektüel" çabasından daha üstün bir iştir.

Bugün, kimya, dişçilik, eczac1lık, vb. gibi disiplinlerin ancak laboratuvar çalışmaları içinde tamamlanabildiği bütün üniversitelerce kabul edilmiş bir şeydir. Ama nedense, tiyatro gibi yoğun bir teknik bilgiyi gerektiren sanat dallarında genellikle entellektüel düzeyde kalınmakla yetinilir ve dikkat tarih ve kuram üzerine çekilir. Bu yanlışı düzeltmek için üniversitelerdeki tiyatro bölümlerinin ne amaçla kurulduğunu saptamak gerekir.

Üniversitelerdeki tiyatro bölümleri ne için kurulmuştur? Kültür ataşeleri yetiştirmek için mi? Kültürleri genişletilmiş memur imâl etmek için mi? Ya da tiyatro üzerine biraz daha fazla konuşabilecek eylemsiz aydınlar ortaya çıkartmak için $\mathrm{mi}$ ?

Hiç kuşkusuz, üniversitelerin tiyatro bölümleri bu amaçlar için kurulmuş değillerdir. Ancak tiyatro alanında yüksek değerde kişiler yetiştirebilmek için, o kişilerin sonraki yaşamlarında profesyonel, başka deyişle ustalaşmış olmalarına, onların bilgi ve becerilerine gidecek yolu üniversite eğitimi sırasında açmış olmak zorunludur. Tiyatro eleştirmenlerinin yeterli teknik bilgisi, idarecilerin gerekli kültürü, yönetmenlerin dünya görüşü, geniş kültürü ve teknik bilgisi, oyuncuların bir kültür dağarcığı olmasında yükümlülük taşıyan en yüksek kurum üniversitelerin tiyatro bölümleriđir. Ủniversitelerde tiyatro öğrenimi kapsamı içinde kuram ya da deneyden biri savsaklanacak olursa, 
yarım yetişmiş mezunlar ortalı̆̆ı saracaktır ve bunlar kısa bir süre sonra bu alanın çeşitli işçilerine yabancılaşacaklardır. Oyun yazarları ve eleştirmenler yalnızca kuramda kalacaklar, öbür yanda yönetmen ve oyuncu tiyatronun yalnızca uygulama alanında sinurlanacaklardır. $\mathrm{Bu}$ da bir sağırlar sövüşmesini ortaya çıkaracaktır. Bunun için de, yönetmenler ve oyuncular eleştirmeni suçlarken, eleștirmen de onları seyirci gözünde küçük düşürecektir.

Kanımca, tiyatro eğitiminde ne kuram ne uygulama ötekinden daha önemli değildir; bunlar birbirini tamamlayan birimlerdir. Önemli olan, öğrencinin düșünce ve hayal etme yeteneğini geliștirmektir. Bu da yalnızca kuramsal derslerle çözümlenemez; kuramlar, uygulamalarla sahne üzerinde canlandırılmak zorundadırlar. Yoksa ölü kalırlar. Örneğin, bir oyun üzerinde yapılan tartışma, sahne üzerinde sürdürülebilmelidir. Bunun için de, eğitilmiş oyuncu gereklidir; metin üzerinde ortaya çıkan sorunlar en doğru biçimde sahne üzerinde çözümlenebilir. Oysa bugün için oyunculuk eğitimi henüz tam anlamıyle üniversiteye girmediğinden ve uygulamalarda eğitilmemiş, tekniği olmayan öğrenciler kullanıldığından yapılan iş, Titania'nın o güzel ormanında izcilik etmekten öteye gitmemektedir. Oyunculuk eğitiminin girmediği tiyatro bölümlerinde de uygulama çalışmaları yetersiz kalmaktadır; çünkü bir oyunun etkili ve anlamlı bir biçimde seyirciye aktarılmasında eğitilmiş oyuncunun katkısı en önde gelir. Amatör oyunculukla yürütülen uygulamaları seyretmek, kanımca, Mozart'1 tek parmakla çalan birini dinlemek gibi bir şey oluyor.

Üniversitelerin tiyatro bölümlerinde kuram ile deneyi bașarılı bir biçimde yürütebilmek için amatör oyunculuktan kaçınmak ve oyunculuk tekniğini önemsemek gerekmektedir; ancak eğitilmiş oyuncuyla yapılacak uygulama çalışmaları ile akademik öğretim çağdaş yaşam koşulları ile bağdaştırılabilir.

$\mathrm{Bu}$ düşüncelerin 1şı̆̆ında asıl konum olan tiyatro yönetmeninin eğitimine geçmek istiyorum. Çağımızın tiyatro tarihinin, sahneye oyun koyma sanatının tarihi olduğu çağdaş incelemecilerle kabul edilmiş bir gerçektir. Bugünkü anlamda tiyatro yönetmeni, yüzyıl gibi kısa bir geleneğe sahip olmasına karşın, bugün tiyatroya yol gösteren en önemli gü̧ durumundadır. Çağdaş tiyatro, varlığını ve geliş̧imini büyük tiyatro yönetmenlerinin çallşmalarına ve yaratıcllkklarına borçludur. Yazar başta olmak üzere, o, tiyatronun bütün öğelerini denetleyen, onlara ne yapacaklarını gösteren ve bu öğeleri uyumlu bir biçimde tümleştiren bir otorite olmuştur. 
Çağdaş yazar, oyununu kesin olarak kağıda geçirmeden önce, yönetmenin laboratuvar çalışması içinde bulunmakta ve onun yönetimi altında oyununu kurmaktadır. Ünlü yönetmenlerin bir bölümünün aynı zamanda oyun yazdıklarını da izleriz. Bazan da yazar, yönetmen olarak da çalışmaya eğilim duymaktadır. Bütün bunlar yönetmenin birleștirici, bütünleyici estetik gücün temsilcisi olmasından ileri gelmektedir. Uygarlığın gittikçe hızlanan gelişmesine paralel olarak gelişen tiyatroda da, tiyatro yönetmeninin bașdöndürücü bir gelişmesi olduğu bir gerçektir. Öyleyse, bir ülkenin, kendi tiyatrosunu yenilemesi ve onu bir gelişmeye sokabilmesi için en başta düşünmesi gerekli olan işi de tiyatro yönetmenin yetişmesi olmalıdır.

"Sürekli bir devrim" olan tiyatroda yönetmenin görevleri ve katk1ları bir haylidir. Onun temel görevi, "gerçeğin görünüşünü değiştirmek değil, gerçeği gizleyen örtüleri kaldırmaktır". Bunu yapabilmek içinde, yönetmen olacak kişinin yaşamdaki çelişkilerin bilincine vararak bir esnekliğe ve yüceliğe erişmesi gerekir. Bir yandan kendini geliştirirken, öbür yandan da yazarı, oyuncuyu ve seyirciyi ileriye götürmek zorundadır. Bunun için de, gerçek yönetmen kendi kişiliği içinde yönetmen-eğitmen, yönetmen-sanatçl ve yönetmen-idareci niteliklerini kaynaştıran kişidir. $\mathrm{O}$, bir yandan yaratırken, öbür yandan bulgulara yönelen bir bilim adamı, tiyatronun bütün öğelerini düzenleyen bir örgütçü, doğruyu ve güzeli kaynaștıran bir estetikçidir.

Tiyatro yönetmeni, çoğu kez bir orkestra yöneticisine benzetilir. Orkestrayı yönetecek kişi, nasıl değişik çalgıların yeteneğini ve özelliklerini bilmeden onları bir arada yönetemezse, tiyatro yönetmeni de elindeki çeşitli sanat dallarının niteliklerini ve kapsamlarını bilmeden bir tiyatro olgusunu varedemez. Ayrıca, eldeki bestenin musiki açısından biçimi, bölümlerinin birbirleriyle olan bağlarını bilmeden bir orkestra çalıştırılamadığı gibi, tiyatroda da eldeki oyunun biçimi, bu biçimin getirdiği zorunlu ilişkiler bilinmeden bir uygulama yapılamaz. Hatta tiyatroda oyun sahneye koymanın bir açıdan daha zor olduğu kanısındayım. Çünkü musiki alanında değer birimi olan "nota" saptanmış sesleri kapsar; oysa tiyatroda değer birimi olan "sözcük", sözlük anlamında kullanılmadığı için, önceden saptanmamış olarak yönetmenin karșısına gelir. Tiyatroda her sözcük, o sözcüğü kullanan kişiyle, o sözcüğün kullanıldığı zamanda ve o sözcüğün kullanıldığ durum ile anlam ve renk yönünden değişir. Ayrica sözcüğün oyuncunun hareketi ile sinkronizasyonu, aynı sözcüğ̈̈n çeşitli oyunlarda, oyunların değişik sahnelerinde ayrı bir değer kazanmasını getirir. 
Bazan bir sözcüğün, sözlük anlamının tam karşıtı anlamda kullanıldığı olur; tiyatroda hareket, herhangi bir sözcüğü, sözlük anlamından çok değişik bir yöne kaydırabilir. Seyircinin, genellikle duydukların. dan çok gördükleriyle etkilenmesi dikkate alınırsa, bir oyun kişisinin, bir durumun ya da bir çatışmanın sözcüklerden önce hareketle anlaşıldığı bir varsayım olmaktan çıkar. Ayrıca, sahne üzerinde kullanılan sözcüklerin iki değișik yönde etki alanı vardır: Bunlardan biri oyuncuya, yâni sahne üzerinde dinleyene ve onunla birlikte yaşayana; öbürü de seyirciye, yâni salonda oturup dinleyene ve yine onunla birlikte yaşayana yöneliktir. Yönetmen, birinci etki alanı ile öbür oyuncunun hareketini hazırlayıp karakter özelliğini ortaya çıkarırken, ikinci etki alanı ile salonda oturan yüzlerce seyirciye, aynı anda, doğru olanı vermek zorundadır.

Bu kadar zor bir işi başaran yönetmen bir yaratıcı mıdır, yoksa bir yorumcu mudur? Yönetmenin genellikle yalnızca bir yorumcu olduğu üzerinde durulur. Yorumcunun yaratıcı yanını burada tartışmak istemiyorum. Kanımca, yönetmen, bir yazar, bir ressam, bir şair kadar yaratıcı olmak zorundadır. Bir sahne yapitının kusurlu yanlarını düzelten, buđama ve eklemelerle tamamlayan, estetik bütünlüğü ortaya çıkaran bir uzman-sanatçı olarak aynı zamanda bir yaratıcıdır da. O bir yazar gibi, sahneleri değerlendirerek, bir şair gibi oyunun atmosferini kurarak, bir mimar ya da ressam gibi sahnedeki görünüşü. yaratarak görevini yerine getirir. Eğer yönetmen yalnızca bir yorumcu olsayd1, o zaman Shakespeare'in oyunları, kendi döneminde nasıl oynaniyorsa, bugün de öyle oynanacak ve tiyatro olarak pek ilginç yanı kalmayacaktı. Çünkü yalnızca yazara ya da metne bağlı bir yorumcunun doğru yorumu, yüzyıllar geçtiği halde, aynı kalan edebiyat yorumcusunun paralelinde olacak ve tiyatronun yaşamının sürdürmesinin temel nedeni olan "çağını yaşamak" niteliği de ortadan kalkacaktı. $\mathrm{Bu}$ da tiyatronun sonunu getirecekti. Çünkü tiyatro büyüsü (evrenselliği) ile varolur, güncelliği (tarihselliği) ile yașar. Edebiyat yorumcusu için bir yapıtın anlamı her çağda aynıdır; ama tiyatro yönetmeni, ikinci bir yazar olarak bir yapıtı yeniden düzenliyebilir, eklemeler ve budamalar yaparak o yapıtı içinde yaşanan gerçeklere en yakın biçime getirir. Yönetmenin yalnızca yorumcu olmadığına başka bir örnek de, onun, çeşitli sanat dallarını birleștirerek bir estetik bütünlüğe gitmesidir. Gerçek yönetmen, yazarın yaratışını aktarmakla kalmaz, ona kendi yaratışını ekliyerek seyirci karşısına çıkar.

Şimdi gerçek yönetmenin özellikleri üzerinde kısaca duralım. Önce yönetmenin güç kaynaklarını ele alalım. Bunlar dünya görüşü, 
kişisel yaratıcllık ve bilimsel yetenek'tir. Yönetmenin bu güç kaynakları, edebiyat, musiki, sinema, mimarlık, resim, vb. gibi sanatlarla, psikoloji, sosyoloji, tarih, felsefe, dil, folklor, vb. gibi disiplinlerle ve dekor, giysi, ışıklama, ses tekniği, oyunculuk, vb. gibi teknik bilgilerle beslenmesi gerekir. Onun güç kaynaklarını vareden yapısı da kendine özgüdür. Genişlemesine bir görüş açısı olan gerçek yönetmen çevresindeki ve dünya yüzündeki olayları yakından izleyen uyanık ve bunları yorumlayabilen bir kişidir; bunun için de geniş ve kesin bir kültür yapısını, dolayısıyle üstün bir beğeni aşamasını içerir. Oyuncu ve öteki sahne sanatçılarıyle olan ilişkilerinde başarı sağlıyabilmek için sanatçı karakterinden anlayan bir pedagog ve aynı zamanda onları yönetebilecek, disiplini getirebilecek bir otorite olmalıdır.

Bir eğitmen, düzenleyici, pedagog, estetikçi, yaratıcı olan yönetmenin en büyük gücü öz-eleştiri yeteneğinden gelir. Çağımızın oyunculuk yönteminde atılımlar yapan Jerzy Grotowski'nin, "oyunculardan yapmaların istediğinin iki mislini yönetmen kendinden beklemelidir," demesi öz-eleștirini vurgulayan bir sözdür.

İşte bu noktada yönetmenin sorumluluklarına değinebiliriz. Tiyatronun içeriği açısından yönetmenin sorumluluğu, yönetmenin yazarla, oyuncuyla ve seyirciyle olan ilişkilerinde yol gösterici ve eğitici oluşudur. O yazarın yetişmesine ve ustalaşmasına yardım ettiği gibi, oyuncularl eğitmek ve onlara yol göstermeyi de üzerine alır. Seyirciye karşı daha büyük bir sorumluluğu vardır: Güçlü ve etkili bir sanat yoluyla, ona çă̆ının yorumunu yapmak, sorunlarını açmak ve insanlığın gelişmesinde en büyük etken olan düşünme ve duyma alışkanlığının yerleştirilmesinde katkısı olmaktır.

Tiyatro içindeki görevi ve sorumluluğu bu kadar önemli olan yönetmen tiyatromuzun gelişimi içinde nereye kadar önemsenmiştir? Türk tiyatrosuna herhangi bir biçimde damgasını vuran bir yönetmen var mıdır? Türk tiyatrosunun geliştirilmesinde en önemli rollerden birini oynayacak olan yönetmen Nasıl yetiștirilecektir? Son sorumuzu da şöyle sorabiliriz: Tiyatro yönetmenin yetiştirilmesi için bir eğitim ve öğretim yöntemi olabilir mi?

Tiyatromuzun gelişimi için, yönetmenin öneminin ne kadar büyük olduğunun bugün de kavrandı̆̆l düşüncesinde değilim. Genellikle, yorgun oyuncuların ya da bir topluluğun başındaki oyuncunun yönetmen olarak kabul edildiği bir tiyatro ortamunda, yetenekli, yeteneksiz herhangi bir sanatçının yönetmen olabileceğine inananların çoğun- 
lukta olduğu bir tiyatro çevresi içindeyiz. Dünya tiyatrosunun gelişiminde çok gerilerde kalmis olan "yıldız oyuncu yönetmen olur" anlayışı tiyatromuzda hâlâ yaygin bir uygulama alanı bulabilmektedir. Bunun için de, genellikle tiyatro yapıtının değerini yükseltmek yerine, o yapıtın çok altında kalan sahne çalışmaları tiyatromuzun atılım yapmasını engellemektedir. Bir oyunu sahneye koyan kimse, çoğu kez seyirciyi, oyuncuyu ve yazarı pek dikkate almadan yalnızca perdenin açılması için alışagelinmiş, kalıplı bir çalışmanın ötesine gidememektedir. Duyarll ve başarll oyun düzenleri ise pek seyrek karşımıza çımaktadır. Çünkü dünya görüşünün 1şığında duyarlı sanatçıların tümü sahneye oyun koyma yeteneğinde olmadiklarl gibi, yetenekli olanlartn elinde de çoğu kez gerekli olan malzeme yoktur. Malzeme derken, en başta çağdaş bir teknikle yetişmiş oyuncuyu kastetmekteyim. Böylece, Türkiye'de başarılı ve seyredeni etkiliyen bir oyun düzeni çok seyrek ortaya çıkmaktadır. Yöntemin ve tekniğin geri düzeye atlldığı böyle bir tiyatro ortamında, tiyatromuza damgasını vuracak, kişiliğini kabul ettirecek bir yönetmen elbette var olamaz!

$\mathrm{Bu}$ noktada, tiyatro yönetmeninin nasıl yetiştirileceği, onun için nasıl bir eğitim ve öğretim yöntemi uygulanabileceği sorusunun yanıtını vermek gerekiyor.

24 mayıs 1940 tarihinde yürürlüğe giren 3829 sayılı Devlet Konservatuvarı Yasası'nda, iki ana bölüm üzerinde durulmuştu: Musiki ve Temsil. Bu yasaya göre, Konservatuvarda tiyatro öğrenimi, biri hazırlık, ikisi orta ve ikisi yüksek olmak üzere beş yıldı. Öbür yanda, Konservatuvar için yapılan İ́tüzük'te Tiyatro Bölümü üç değil, dört ana bölüme ayrılmıştı. İçtüzüğün 9. maddesine göre, bunlar Opera, Tiyatro, Balet ve Rejisörlük bölümleriydi. Yasa'da göremediğimiz Rejisörlük Bölümünde, opera ve tiyatronun yüksek kısmından mezun olanlara özgü iki yıllık bir uzmanlık çalı̧̧ması yaptırılması istenmekteydi. Ne yazık ki, günümüze değin, önemi Türk tiyatrosu için büyük olan $R e$ jisörliik Bölümü çeşitli ihmal ve olanaksızlıklar nedeniyle çalıştırılmamıs ve yine bugüne dek hiç bir konservatuvar ögrencisi, tiyatro yönetmenliği alanında, Türkiye sınırları içinde, uzmanlık eğitimi görmemiştir. Bunun için de, Reinhardt'ın yetiştirimelerinden ünlü oyuncu Carl Ebert'in bütün çabalarına karșın, bu bölüm kurulamamış; o gittikten sonra bu bölümün kurulması için zaman zaman gösterilen çabalar çeşitli nedenler yüzünden gerçekleşememiş, hatta bir yönden engellenmiştir. Bu yüzden, devletin ödenekli tiyatrosu yalnızca bir "aktör tiyatrosu" olarak kalmış ve bu alanda yetişmiş uzman ve yetenekli yö- 
netmenler olmadığı için bu kurum, başka nedenlerin de zorlamasıyle, gerilemeye başlamıștır. Ancak kanımca, Devlet Tiyatrosu'nun estetik alanda ileri bir attllm yapamamasinin en önemli nedenlerinden biri gerçek yönetmenin yetiştirilmesinde konservatuvartn gösterdiği ihmal ve vurdumduymazlikttr.

Tiyatro yönetmeninin eğitimi konusunda, ülkemizdeki ilk atılım 1964 / 1965 ders döneminde çalışmaya bașlayan Ankara Üniversitesi, DTC Fakültesi, Tiyatro Kürsüsü ile geldi. Sekiz sömestirlik, yâni dört yıllık bir eğitim programı içinde, tiyatro yönetmenliği uygulamalı olarak "Sahne Çalışması" dersleri içinde gerçekleştirildi. Ayrıca, bu sahne üzerindeki laboratuvar çalışmasına yardımcı olarak dört sömestir süren "Reji Problemleri" ile yine sahne üzerinde alıştırmalarla altı sömestirde gerçekleştirilen "Reji Deneyleri", tiyatro yönetmeninin eğitimini bütünleyen konulardır.

"Sahne Çalışması" dört yıl içinde, üç evrede tamamlanmaktadır. Bunlar: 1- Organik Değerlendirme, 2- Plastik Değerlendirme, 3-Teknik Değerlendirme evreleridir. Birinci sömestirden itibaren sahne üstü uygulamalı çalışmalarının başladığı bu eğitimin Organik Değerlendirime evresinde "Yorum Yöntemi", "Sahneler Üzerinde Çalı̧̧ma", "Budama" ve "Oyun Düzeni Defteri" konuları yer alır. Plastik Degerlendirme'de "Oyuncunun Yönetmen tarafından sahne üzerinde değerlendirilmesi," "Kișileştirmenin İlkeleri", "Sahne-Seyirci İlişkisi", "Sahnenin İşlevi Açısından Değerlendirilmesi", "Oyuncu Seçimi", "Provalar", ayrıca yönetmenin oyun düzeni için gerekli olan "Tasarım", "Optik Yorum", "Hareket Yapımı", "Hız-Tartım-Zaman Ölçüsü," "Sözsüz Oyunla Dramatizasyon" bu bölümde yer alır. Oyun düzeni üzerine yapılan çalışmalar yalnızca çerçeve sahne kapsamı içinde değil, aynı zamanda ortada oyun kavramı açısından da ele alınarak uygulanır. Teknik Değerlendirme evresinde "Dekor ve Işılklama Tekniği-Estetiği”, "Aydınlatma Araçları", "Karartıcılar", "Giysi ve Makyaj", "Makyaj Araç ve Gereçleri," "Makyaj Yapımı", "Sahne Etmenleri", "Oyun Musikisi", "Aksesuvar-Butafor" gibi konular yer alır.

Yukarda da belirttiğim gibi, bu evrelerdeki bütün çalışmalar gerektiği biçimde uygulamalarla ortaya çıkarılır ve öğrenciler yanlışlarını bu uygulamalarda görerek düzeltirler. Ayrıca, bu evrelerin tümünde sırayla ve daha çok kendilerini ilgilenđirdiği konularda hem kafayla hem de bedenen çalışırlar. Sözgelimi, dekorda çalışacak olanlar, bu dekorun yapımı için yorumlarını yönetmenle tartışılar, gerekli pl- 
anlarını hazırlarlar ve bunu sahne üzerinde gerçekleștirmek için marangozhanede, boyahanede arkadaşlarıyle birlikte, başka deyişle imece ile çalışmaya girerler. "Sahne Çalışması" dersleri kapsamı içinde, deneysel çalışmayı bütün öğrencilere sağlyabilmek için ders dönemi sonlarına doğru oynanmak üzere bir oyun seçilir ve öğrenciler çeşitli görevleri üzerine alırlar. Bu çalı̧̧malarımızda tek aksayan, oyunculuk eğitimi olmadığından, yetenekli amatörleri kullanmamız ve doğal olarak bir bütün olan tiyatroda, oyunculuk konusunda aksamamiz, bu aksamayla öteki alanlarda yapılan başarılı çalışmalara gölge düşürmemizdir.

Başta da söylediğim gibi, sahne üzerinde yapılan her çalışma için oyunculuk tekniği en başta gelen gereksinme olduğu için, yönetmenin eğitiminde de tekniği olan, konuşmasını, hareketlerini ve dikkatini toplamayı belli bir uyum içinde getirebilen elemanlara mutlaka intiyaç olmaktadır.

Tiyatro yönetmeninin eğitimi içinde, bu eğitime katılan her öğrencinin tiyatro yönetmeni olacağı da savunulamaz. Bu eğitim içinden yine en yetenekli ve sorumluluklarının bilincine varmış, kendini yetiştirmek için göstermelik olarak değil de, inanarak bu işe emek vermiş kişiler ilerinin yönetmeni olarak yetişebilirler. Yönetmen olamayanlar ise tiyatronun mutfağında çalışmıș kişiler olarak ileriki yaşamlarında tiyatroyu daha tutarlı ve bilerek değerlendirme yoluna gidebilirler. Sözgelimi, tiyatro eleştirmeni, dramaturgu, tarihçisi ve incelemecisi olarak laboratuvar eğitimi görmüş kişiler olarak ayaklarını daha sağlam yere basabilecek kişiler olarak ortaya çıkarlar.

Burada bir noktaya kısaca değinmeden geçemiyeceğim. Her alanda olduğu gibi, ülkemizde, bu alanda da bir güç kaybı olmaktadır. Tiyatro Kürsüsü mezunlarının büyük bir bölümü televizyonda görev almakta, onların asıl yeri olan Devlet Tiyatrosu ise bazı bürokratik ve keyfî neđenlerden dolayı kapılarını bu değerli gençlere kapalı tutmaktadır. Oysa sekiz sömestir, öteki derslerle birlikte, tiyatro yönetmeni için gerekli eğitimi oldukça yoğun bir biçimde gören bu mezunların başarılı olanlarının en azından Devlet Tiyatrosu'ndaki "Reji Asistanlığı" kadrosuna alınmaları gerekir. Ne var ki, tiyatro yönetmeninin önemini henüz hakkıyle anlıyamamış bir çevre içinde, doğal olarak "yönetmen yardımcılığı" görevinin önemi nasıl anlaşılabilir ki? Bu anlayış sürdükçe Devlet Tiyatrosu'ndaki "Reji Asistanlığı" göstermelik olarak kalacak ve bu kiși bugünkü gibi, sahneye oyun koyanların ayak işlerine koşacaktır. Çünkü bu kişi,ilerinin incelemecilerine 
1şık tutacak, tiyatro tarihimizin en önemli konularından biri olan uygulama tarihi için gerekli olan Oyun düzeni Defteri tutmasını bilmediği için de sahneye oyun koyanın buyruklarını yerine getirecek bir emireri durumundan ileri gidemiyecektir.

Oysa gerçekte, yönetmen yardımcıllı̆ı ilerinin tiyatro yönetmeni olacak kişilerine deneyleri getiren bir hazırlık döneminden başka bir şey değildir. Ancak yönetmen yardımcısı olacak kişinin de belli bir süre bu eğitimi görmüş, gerekli laboratuvar çalışmasını tamamlamış olması gerekir. Birçok kavramın birbirine karıştırıldığı, yöntemin ve tekniğin anlaşılmadığı, belli bir disiplinsizliğin egemen olduğu bir çevrede nasıl yönetmenler duygusal olarak seçiliyorsa, yönetmen yardımçlığına getirilecek kişiler de aynı ciddiyetten uzak bir anlayış içinde seçileceklerdir.

Türk tiyatrosunun daha birçok alnında gördüğümüz yöntemsizsizlik ve dă̆ınıklık kendini en çok tiyatro yönetmeninin çalışmasında hissettirmektedir. Çünkü bütün tiyatro birimlerini bir araya toplayan, çeşitli sanat kollarını, bir amaç için, uyumlu bir biçimde ve estetik bir bütünlük içinde kaynaştırması gereken yönetmen henüz ortada yoksa, o tiyatronun birçok yanı da aksayacaktır. Buna bir son vermenin zamanı gelmiştir. Üretimi bu topluma yararlı bir duruma getirebilmek için, bir fabrika görünümünde olan tiyatronun kollektif çalışmasını artık bilime, tekniğe ve yönteme dayamanın zamanıdır. Ưstün ve seçkin sanat olayları ancak bilimle, teknikle ve yöntemle gelebilir.

Yönetmen, tiyatronun yol göstericisi, yetkileri ve sorumlulukları sınırsız; Marko Paşa olmak istemediği halde, oyuncuların, teknik adamların ve tüm tiyatro görevlilerinin dert babası; bir oyunu sahneye koyarken diktatör olmak istemediği halde, diktatör olmak zorunda olan; başlangıçta yolun sonu nereye gidiyor, onu tam olarak göremediği halde, yol göstermek zorunda olan bir sanatçıdır. Böyle bir sanatçı, uzun yılların sahne deneyleriyle ustalaşmış, sahne üzerinde ortaya çıkabilecek her sorunun yanıtını bilen bir kimsedir. Ancak teknik açıdan ustalaşmış böyle bir yönetmen yaptığının bilincinde değilse, çağını kovalamıyorsa, bir sanatçı olarak çevresindeki olaylara, dünya yüzündeki sorunlara karşı duyarlılığını yitirmişse, her çalışmasıyle yeni bir kapı açmıyorsa, tiyatroya olan zararı yararından daha çoktur. Çünkü tekniği bilen, deneyi olan, ama her şeye ve her olaya karşı nasırlaşmış bir kişi, olsa olsa öldürdüğü tiyatronun ölüsünü yıkayabilir. 
Peter Brook, bu tür yönetmenler için şöyle der: "Öldürücülük her zaman tekrarla birlikte gelir; öldürücü tiyatronun yönetmeni eski formülleri, eski yöntemleri, aşınmış esprileri, eski etkileri, köhnemiş sahne başlangıçlarını ve bitişlerini kullanır." Öyleyse, sahneye oyun koymanın temel ilkelerini bilmek yönetmen olmak için yeterli değildir. Hiç bir şey varolmadan yenilenemez, yenilenmedikçe de varlığını sürdüremez. Bir şeyin yenilenebilmesi, geliştirilebilmesi ve yeni bulgularla değiştirilebilmesi için her şeyden önce varolması gerekir. Onun yaşaması için de sürekli olarak kendini yenilemesi ve değiştirmesi zorunludur. 